\title{
MALTESES EN ARGELIA (1833-1900): ENTRE EL RECHAZO Y LA ACEPTACIÓN
}

\author{
DJAmel Latroch \\ Universidad de Mostaganem
}

\begin{abstract}
Resumen
Estudio histórico y estadístico de la presencia de población maltesa en Argelia durante el periodo de I833 a I900. A través del análisis de las fuentes históricas, se reconstruye cuantitativamente el volumen de la migración desde la isla de Malta a la Argelia de la primera colonización francesa, revelando la respuesta ambivalente tanto del gobierno colonial como de la población. Al mismo tiempo se explora lo que supuso la migración a Argelia en el contexto de la historia contemporánea de Malta como un destino predilecto por la vecindad geográfica y cultural.
\end{abstract}

Palabras clave: Malteses, Argelia, migración, política colonial, sociología.

\section{En homenaje a Juan Bautista Vilary Emilio Sola Castaño}

\section{Planteamiento inicial}

Las migraciones europeas hacia Argelia han gozado de numerosas publicaciones y aproximaciones por parte de historiadores interesados en precisar el papel de las diferentes comunidades extranjeras en territorios norteafricanos y su relación con la colonización francesa. En este sentido, la comunidad española en Argelia es una de las más privilegiadas al haber sido objeto de múltiples estudios, siendo el profesor Juan Bautista Vilar el pionero en estudiar todo lo referente a este proceso migratorio.

No obstante, las migraciones de origen mediterráneo no se limitaban exclusivamente a los españoles peninsulares. Los italianos, los mahoneses y los malteses, fueron efectivamente otras comunidades mediterráneas que se establecieron en Argelia bajo la colonización del siglo XIX. Estas comunidades tuvieron, de igual manera, su impacto, aunque de menor importancia, en la sociedad argelina, e incluso marcaron sus propios espacios geográficos diferenciándose entre ellas, como el caso de 
la presencia maltesa a lo largo de la franja mediterránea del este argelino. Esta comunidad no ha sido todavía objeto de estudios por parte de los investigadores, a pesar de su numerosidad y sus características especificas, salvo contados trabajos, como los de Ramiro Vadala en igı, Charles Price en 1954 y algunos trabajos del maltés Marc Donato, quien desde una perspectiva global la sitúa dentro de sus diferentes dimensiones tanto sociales como históricas, explicando las causas directas e indirectas y el modo de establecerse en tierras argelinas ${ }^{1}$.

Por otra parte, la presencia de estas diferentes comunidades mediterráneas no coincide con la política migratoria de las autoridades coloniales, sobre todo en la primera década, donde Francia no había precisado todavía cuál iba a ser su futuro en tierras africanas ${ }^{2}$. Sin embargo, a partir de 1847 se consolida la empresa colonial francesa y empieza con ella el control de la emigración. Cabe mencionar que la política migratoria francesa depende del país de procedencia del emigrante, y se caracterizó por dos facetas: la primera, la "oficial" destinada a los emigrantes europeos no mediterráneos, y la segunda, la "poco deseada”, reservada a la emigración mediterránea ${ }^{3}$.

Desde el comienzo de la colonización, las autoridades francesas establecieron el perfil ideal de los emigrantes que deseaban y esperaban: preferían suizos, belgas y alemanes, a los que les daban la bienvenida y les abrían todas las puertas para instalarse en suelo argelino ${ }^{4}$. Eran ricos, religiosos, leales y tranquilos, pero con desventaja en su inadaptación a la

1 Marc Donato, L'émigration maltaise en Algérie et Tunisie au XIXème siècle, Mémoire de DEA, Université Aix-Marseille, 1986. Idem, Elisa, la maltaise: histoire des maltais d'Algérie (1830-1920), Niza, Gandini, 2002; Lémigration des maltais en Algérie en XIXe siècle, Montpelier, Africa Nostra, 1985. Los profesores norteamericanos David P. y A. Smith también han estudiado la composición de la población europea, con mención particular a los malteses en el este argelino.

2 Yevette Katan, “Le voyage organisé des émigrants parisiens vers l'Algérie”, Emigration française: étude de cas: Algérie, Canada, Etat Unis, París, Publication de la Sorbonne, Série International, 1985, núm. 24, pp. 18-45.

3 Émile Temime, "La migration européenne en Algérie au XIXe siècle : migration organisée ou migration tolérée”, Monde arabe, migration et identité, Revue de l'Occident musulman et de la Méditerranée, 1987, vol. 43, p. 33.

4 Los alemanes eran los más deseados por las autoridades francesas. La propaganda y la publicidad oficial para captarles manifiesta la voluntad francesa para con "los deseados". Para acercarse a este punto véase Fabienne Fischer, Alsaciens et lorrains en Algérie: Histoire d'une migration (18301914), Niza, Jacques Gandini, 1999, p. 9 y ss. 
climatología norteafricana. En efecto, el informe de la comisión presidida por el general Bonet enviada a Argel en I833 concluye prefiriéndose a los alemanes y suizos como colonos más deseados: "les allemands et les suisses, qui vont au Nouveau-Monde chercher des terres incultes, se sont que nous devons le plus désirer de voir venir dans nos possessions d'Afrique" 5 . Por otra parte, los inmigrantes mediterráneos (españoles, italianos, mahoneses y malteses) se instalaron espontáneamente poco después de 1830 .

La emigración espontánea, de iniciativa personal, es una de las características del ciclo migratorio mediterráneo iniciado principalmente por españoles en la región de Orán y ciudades colindantes; a diferencia de los malteses, que preferían la región centro-oriental,instalados cerca a los puertos y en zonas muy cercanas a ellos. Puede confirmarse hasta cierto grado que la colonización de Argelia fue iniciada gracias al éxodo de la emigración europea en general y con mención particular a la mediterránea donde, efectivamente, las estadísticas oficiales de la época comprendida entre 1830 a 1847 dan crédito a ello.

\section{LOS INMIGRANTES MEDITERRÁNEOS EN LA POLÍTICA MIGRATORIA FRANCESA}

Desde el comienzo de la colonización Francia intentó, de manera sistemática, buscar cauces para controlar el desequilibrio demográfico entre los naturales del país y los europeos, temiendo la supremacía de argelinos sobre franceses, lo que podía poner en riesgo el futuro de la colonización. Para ello, se optó por permitir tolerándose la llegada de flujos migratorios mediterráneos encabezados por españoles, malteses e italianos para instalarse a lo largo del litoral argelino ${ }^{6}$. Sin embargo, los franceses ya residentes en Argelia quedaban a la espera de las decisiones de "la Metrópoli" de cara a la emigración al norte de África por falta de claras perspectivas en su política colonial y por la improvisación que mostraban. Cabe señalar que desde I833 hasta I847 fueron años muy duros para los colonos franceses que no pudieron resistir a la nueva vida y por

5 Procès-verbaux et rapports de la Commission nommée par le Roi le 7 juillet 1833, París, Imp. Royale, 1834, p. 92.

6 Kamel Kateb, Européens Indigènes et juifs en Algérie (1830-1962), París, Cahier N 145, INED, 2001, p. 28. 
consiguiente prefieren retornar a sus tierras natales: sobre 80.000 pasajes gratuitos otorgados a los franceses para desembarcar en Argelia en I837, 70.000 retornaban a su país de origen ${ }^{7}$. Y poco más tarde, entre 1842 a I846 se registró II8.000 salidas del total de i98.000 entradas.

A parte de estos problemas, hay otros que motivaron de manera directa el retorno de los colonos europeos: las malas cosechas sobre todo en la década 1858 -I867, provocando - a posteriori- una grave crisis alimenticia (hambre) entre I866 a I868 que provocó a su vez una repercusión mediática nacional e internacional ${ }^{8}$. Los fenómenos naturales (terremotos en I839, I846, I851, y las sequías) habían provocado de igual manera la salida de colonos y, al mismo tiempo, se demoró la llegada de otros interesados en instalarse en Argelia ${ }^{9}$. Efectivamente, Francia tuvo dificultades para implantar una comunidad puramente francesa en suelo argelino ${ }^{10}$, a causa del retorno masivo de los colonos europeos, y es que "la France (...) n'a guère réussi à implanter dans sa colonie d'Algérie un peuplement venu de la métropole. D'une certaine façon, ils étaient peu français, ces Européens d'Algérie qui se désignaient eux-mêmes au XIX siècle comme "Algériens" ou "Africains" et au XXe siècle comme "Européens"11.

Para recompensar la pasividad de los colonos a instalarse en Argelia, se toleró la llegada de inmigrantes del Mediterráneo que efectivamente, vinieron por oleadas, superando en ciertas regiones a los mismos franceses, como el caso de los españoles en el Oranesado. No obstante, poco después de 1836, Francia tuvo que pensar seriamente en controlarla y, por ello, se tomaron decisiones para su restricción. Paul Leroy recoge en su obra L'Algérie y la Tunisie la decisión ministerial que alertó del peligro y

7 Colonel de Ribourt, citado en Paul Leroy-Beaulieu, L'Algérie et la Tunisie, París, Librairie Guillaumin, 1887, p. 35.

8 Bertrand Taithe, "La famine de 1866-1868 : anatomie d'une catastrophe et construction médiatique d'un événement”, Revue d'Histoire du XIX siècle, 2010, núm. 41, pp. 113-127.

9 Abbé Burzet, Histoire des désastres de l'Algérie 1866, 1867, 1868, Argel, Imp. Centrale Algérienne, 1869, 34-44.

10 Desde 1830 Francia tuvo serios problemas para poblar Argelia. El rechazo de los franceses a instalarse en Argelia causó, efectivamente, insuficiencia poblacional, y casi toda la política colonial en la primera década fue un fracaso. Cf. Alain Lardillier, Le peuplement de l'Algérie de 1830 à 1900: les raisons de son échec, Versalles, Atlanthrope, 1992, p. 17 y ss.

11 Gilles Manceron y Hassan Remaoun, D'une rive à l'autre, La guerre de l'Algérie de la mémoire à l'histoire, París, Syros, p. 91. 
de la preocupación del gobierno francés para:

[...] d'arrêter une immigration trop nombreuse et trop hâtive, d'obvier au désagrément de voir tomber des individus dans la détresse pour s’être inconsidérément transportés dans cette contrée sans savoir les moyens d'y vivre et fixés et assurés», incluso propone medidas para frenarlo: «Le gouvernement français, outre les mesures déjà prises pour empêcher l'immigration spontanée de pénétrer en Algérie, a cru devoir en interdire l'accès dorénavant, jusqu'à nouvel ordre, à tout étranger qui ne pourra établir amplement qu'il a de quoi s'y entretenir ${ }^{12}$.

Coincidiendo con el resultado de la Comisión Bonet de i833, el abogado Eugène Lerminier en un artículo publicado en la prestigiosa revista Revue des Deux Monde (I836), pone de manifiesto la importancia de Argelia como única respuesta a todos los problemas económicos y sociales de la Francia de Louis-Philippe, incitando a todos los franceses a seguir adelante la colonización 'Le sol de l'Afrique est doué d'une grande fécondité qui provoque et récompense le travail. L'agriculture, dont la France a le goût et le génie, peut s'y déployer à l'aise"13. Y añade, dejando constancia del valor de Argelia para la seguridad interna y externa de Francia:

La possession du littoral de l'Afrique est nécessaire, non seulement à l'éclat, muais à la sûreté de notre empire. Nous avons besoin d'une position forte pour contrebalancer Gibraltar, canon toujours béant, toujours armé, et pour avoir dans la Méditerranée l'équivalent de Mahon, qu'un réveil et des inimitiés de l'Espagne pourraient un jour nous rendre formidable. Il importe à notre liberté et à notre commerce dans la Méditerranée de rester propriétaires d'un vaste territoire africain. Alger protège Marseille. Croit-on que les Anglais eussent incendié le port de Toulon si les flottes françaises eussent eu en Afrique d'autres rades et d'autres ports? ${ }^{14}$

12 Paul Leroy-Beaulieu, ob. cit., pp. 31-32. No obstante, por el decreto ley de 18 de septiembre de 1848, Francia intentó organizar la emigración de los franceses y al mismo tiempo intentar asimilar el fracaso continuo de la repoblación de Argelia de la década anterior. Mediante la propaganda y la publicidad, las autoridades francesas querían captar en su mayor parte franceses interesados en instalarse en Argelia. También los alemanes, a partir de 1850, fueron objeto de esta publicidad y propaganda mediante folletos distribuidos en las mismas tierras alemanas y artículos de prensa en periódicos locales en lengua alemana.

13 Eugène Lerminier, "De la colonisation d'Alger”, Revue des Deux Mondes, París, 1836, tom. 6-1, pp. 607-608.

$14 \mathrm{Ibid}$. 
Ahora bien, para igualar la poblacion francesa con el colectivo europeo, Francia permitió a partir de 1847 la instalación de todo tipo de emigrantes, cediendo el paso para que:

[...] arrivent des paysans des régions pauvres du sud-est de la France et de la Corse, des chômeurs des ateliers nationaux de 1848, des condamnés politiques de 1852 , des enfants trouvés, des forçats, des viticulteurs du Languedoc victimes du phylloxera, des Alsaciens-Lorrains de i87i fuyant l'Allemagne, des soldats démobilisés, des émigrants du bassin occidental de la Méditerranée qui échappent à des pays misérables et trop peuplés ${ }^{15}$.

Así pues, la política migratoria de las autoridades coloniales en Argelia dependió de las circunstancias económicas pero, sobre todo, de las políticas de la metrópoli ${ }^{16}$. Y por consiguiente, a partir de I87o, se mostró más favorable a la asimilación de las comunidades extranjeras bajo leyes de naturalización o de concesión de nacionalidad para aquellos mismos que, unos años antes, habían sido los menos deseados, tales como los malteses, italianos y españoles.

\section{Dinámica demográfica maltesa y mediterránea en Argelia}

Estadísticamente hablando, en I833 había I.2I3 malteses censados en toda Argelia, y tres años más tarde se calculan r.802 ${ }^{17}$. A finales de 1836 se sumaban 9.076 extranjeros de origen no francés residentes en Argelia, frente a 5.485 de franceses repartidos esencialmente en Argel, Orán y Bona. El número de malteses ocupaba la tercera escala con los ya señalados I.802, después de italianos (I.845) y españoles (4.592). En I846 se

15 Jean Ferniot, De Gaule et le 13 mai, París, Plon, 1965, p. 13.

16 Sessions Jeneffer, "Le paradoxe des émigrants indésirables pendant la monarchie de juillet, ou les origines de l'émigration assistée vers l'Algérie", Revue d'Histoire du XIXe siècle, 2010, núm. 41, pp. 63-80.

17 Todas las estadísticas que manejamos en este texto están sacadas de diferentes obras: Victor Demontès, Le peuple algérien. Essais de démographie algérienne, Argel, Imprimerie Algérienne, 1906; idem, "Études de démographie algérienne. Les populations européennes. Leur accroissement, leur densité et leurs origines", Revue des Questions Diplomatiques et Coloniales, París. 1900, tom. 10, pp. 193-211; Augustin Bernard, "La colonisation et le peuplement de l'Algérie d'après une enquête récente”, Annales de Géographie, 1907, tom. 16, núm. 88, pp. 320-336; Alain Lardillier, ob. cit.; René Ricoux, La démographie figurée de l'Algérie, París, Masson, 1880 ; e idem, La population européenne en Algérie pendant l'année 1884, Etude statistique, Philippeville, Feuille, 1885. 
contabilizan 8.858 , casi el $40 \%$ del total de los extranjeros censados son residentes en la zona del actual Skikda. En este año, se calcula que había unos ro9.380 europeos en suelo argelino, donde 47.247 son franceses (43\%), 31.528 son españoles (28\%), y el total de las comunidades extranjeras sobrepasa claramente a los franceses por I4.832 almas, es decir, el I4\% del total de la población extrajera en Argelia. En i847, se calcula que había un total de 8.788 unidades de origen maltés, donde 4.6Io vivían en Argel, ocupando la tercera categoría después de los españoles (3I.528) y de los franceses (47.274); y el total de europeos en toda Argelia es I03.610. ${ }^{18}$ Mientras se estima que son 7.307 personas en I85I.

Sin embargo en el censo de I856, I67.640 es el total de los extranjeros residentes en Argelia, donde el elemento francés sobrepasa a las demás comunidades europeas: 92.738 franceses frente a 66.544 de otras nacionalidades. Los malteses suman 7.II4. ${ }^{19}$ Estas cifras vienen desde 1847 en aumento gracias a las políticas migratorias y la empresa colonial de los franceses. En efecto, a partir de las estadísticas de I86i, en un total de 205.888 residentes europeos, había 80.5I7 extranjeros no franceses: españoles 48.I45, italianos II.8I5, malteses 9.378; frente a II2.229 de origen francés. Unos 245.II7 y 3II.462 de extranjeros europeos en los censos de 1872 y I876, donde los malteses censados ascienden a II.5I2 y I4.220 respectivamente, mientras los franceses son I29.60I para el primer año y I45.727 para el segundo.

Cabe mencionar que el factor de la natalidad entre estas comunidades europeas había hecho aumentar el número de los residentes en Argelia y, efectivamente, en el Departamento de Argel desde I830 a I853 se calculan unos 25.4II nacimientos, unos II.755 y 7.734 en los Departamentos de Orán y Constantina respectivamente. Entre i876, I877 y i878, en toda la geografía argelina, había 34.67 I nacimientos de europeos frente a

18 M. E. Carette, «Algérie», Univers ou histoire et description de tous les peuples, París, Firmin Didot, 1856, p. 41.

$19 \mathrm{El}$ doctor René Ricoux en su obra La démographie figurée de l'Algérie (1880) calcula que en el año 1856 había en el territorio argelino 92.750 franceses, 42.218 españoles, y 7.114 malteses, y el total de los europeos alcanzaba 169.186. Estos números son idénticos a los de la obra de Victor Demontés Le peuple algérien: essais de démographie algérienne (1906), salvo que el total de los europeos es de 160.798. también en las dos obras, la totalidad de la población europea en 1861 es idéntico. Réné Ricoux calcula que son 205.888, mientras Demontés estima que son 192.646. Esta inexactitud en los números nos pone siempre alerta al comparar los números. 
32.159 fallecimientos, es decir una diferencia positiva de 2.512; mientras los malteses en estos tres años se calculan en r.572 unidades. Entre los I4.220 malteses censados en I876, había 518 niños nacidos. Generalmente el número de la natalidad oscila entre 400 y 500 anualmente. En los I5.402 —el total de los malteses en I88I- se registraron 569 nacimientos. La estimación de la natalidad en el período comprendido entre I854 a I873 es de 3.695 personas. No obstante, en I884 había 504 nacimientos de padres malteses ( 285 chicos frente a 219 chicas); en este mismo año los niños nacidos de padres malteses y madres francesas son 24 hijos y con italianas 27 nacimientos, y el total de los nacimientos de malteses es de 578. Los nacimientos de los malteses en toda Argelia (I884) no supera ni la mitad de los nacimientos de los italianos que se calculan alrededor de I.279, ni tampoco a los nacimientos entre la comunidad española, que se calculan alrededor de 4.872 de matrimonios legales y de uniones ilegales; mientras en 1886 fueron 584 unidades (I5.333 total de malteses).

Por otra parte y en 1842 , se habían celebrado 84 enlaces matrimoniales entre malteses, mientras los españoles e italianos celebraron 592 y I50 respectivamente. Los matrimonios mixtos o cruzados, otra cara del aumento de la población en Argelia, no tuvieron números sorprendente entre franceses y las comunidades europeas. Desde I830 hasta I877 se celebraron en toda la geografía argelina 23.217 enlaces entre franceses (nacionales) y I4.568 entre extranjeros (franceses no incluidos). Entre franceses y mujeres de nacionalidad europea se calculan a 5.073 mientras entre francesas y extranjeros de sexo masculino (no francés) se calculan a I.808 enlaces matrimoniales, y el total de todos los matrimonios en este período es de 44.8I6, incluidas otras comunidades extranjeras y extranjeros casados con musulmanes y judíos.

En los años I879, I880 y i88I se celebraron 972 uniones entres franceses y mujeres de todo tipo de nacionalidades europeas, no obstante, en los años I882, I883 y I884 había I.I27 de matrimonios mixtos entres franceses y mujeres extranjeras, mientras entre éstas y hombres extranjeros se calculan a 403 uniones. En el bienio I882 a I884 se celebraron 3.43I enlaces matrimoniales entre extranjeros no franceses. Las maltesas eran las menos solicitadas por matrimonio con los franceses. En I884, según 
René Ricoux ${ }^{20}$, se registraron 28 matrimonios entre franceses y maltesas (5 en Argel, I7 en la región de Constantina y ninguno en el Departamento de Orán); mientras se celebraron 84 matrimonios de nacionalidad maltesa donde 39 se celebraron en Constantina. Sobre cien niños nacidos de padres franceses, en 1884, sólo 9 tienen madre maltesa, 62 de madre española y 19 de madre italiana. Los malteses, al contrario, prefieren contraer matrimonio con francesas debido a la situación en que vivían; sin embargo, 38 es el total de matrimonios cruzados entre malteses con mujeres europeas: II con francesas, el mismo número con italianas y I5 con españolas. Hay que recordarse que los malteses en Argelia como en su país de origen siempre tienen la media de cinco a seis hijos por matrimonio y si es de matrimonio cruzado la media es de dos hijos, y siempre se casan siendo muy jóvenes donde los esposos no sobrepasaban los veintiún años y las mujeres - generalmente- dieciocho años a la hora de contraer matrimonio.

La mortalidad maltesa en 1876 y 1886 fue de 373 y 479 unidades respectivamente, cifra bastante considerable en comparación a la totalidad de esta comunidad ${ }^{21}$. Desde 1830 hasta final del siglo XIX, el año más significativo fue el de I889 por la tasa de mortalidad más elevada: 704 frente a 514 de nacimientos. Mientras en 1884 hubo 397 fallecimientos ( 243 varones y I 45 de sexo femenino), es decir unos I 45 nacimientos por Ioo fallecimientos; mientras en I882 casi se igualan las cifras. A partir de 1894, 302 es el total de mortalidad maltesa en Argelia. En la década comprendida entre 1894-1903 se calcula que el total de la mortalidad era de 3.134 personas: I.842 de sexo masculino y r.322 de sexo femenino.

Natalidad por nacionalidad y por sexo en 1884

\begin{tabular}{|c|c|c|c|c|}
\hline Padre/madre & Maltesa & Española & Italiana & francesa \\
\hline Francés & 60 & 432 & 137 & 4.173 \\
\hline Español & 18 & 4.038 & 32 & 90 \\
\hline Italiano & 29 & 72 & 1.052 & 109 \\
\hline Maltés & 578 & 24 & 27 & 504 \\
\hline
\end{tabular}

Fuente: Ricoux René, La population européenne en Algérie pendant l'année 1884.

20 Véanse las tablas al final del texto.

21 Conviene recordarse que hubo muchas epidemias en Argelia y en la zona del Mediterráneo: cólera (1867), tifus y viruela (1868), filoxera (1885), cólera (1886). 
Estas cifras, aunque orientativas, nos sitúan dentro del recorrido panorámico de las diferentes comunidades europeas en Argelia y nos afirman la importancia de la emigración mediterránea en la colonización de Argelia. Los malteses, por otra parte, residen esencialmente en el este argelino, en localidades como Bona, Cala y Colo que son, entre otras ciudades centro-orientales, zonas preferidas por los recién llegados. Éstos instalados muy inmediatamente a partir de I830, aumentan de forma progresiva hasta 1896 (después de la Ley de Naturalización Automática de 1889 se consideraban ya franceses). Es digno de señalar que el auge de la presencia de malteses se sitúa entre I88I a I89I donde se había registrado su mayor número: 15.402 y I4.677 respectivamente ${ }^{22}$. En I886 había en Argelia un total de 15.533 malteses y en I89I y I896 había I4.677 y I2.8I5 unidades respectivamente: un descenso de r.862 unidades.

En suma, esta comunidad en comparación con las demás comunidades europeas - española sobre todo- fue relativamente modesta en sus cantidades. En I872, los malteses, en toda la región del este representan el 73\%, mientras en la región del centro (Argel) representan sólo el 26\% y en el Oranesado, sin embargo, no alcanza el uno por ciento ${ }^{23}$. Desde I85I hasta 1872 se habían ganado del elemento maltés más de 3000 almas. En la región de Bona en 1846, el 40\% de la población europea es de origen maltés. En Orán en I88I, se calcula que había 463 unidades, cifra muy inferior comparándola con los que habitaban Bona (actualmente Annaba). Mientras en 1886 , se había registrado el mayor número de esta comunidad en la región de Constantina, Io.8II. Sin embargo, en el centro argelino se estima que eran 4.I49 unidades y, como es lógico, en el Departamento de Orán no alcanzaban las 573 almas. Cabe mencionar que desde 1833 hasta 1850 la comunidad maltesa sobrepasaba claramente a la comunidad italiana en toda la geografía argelina: I.2I3 frente a I.I22 en el año I833; en r850 se igualan y los italianos se posicionan en las tercera escala justo después de la comunidad española y de los franceses. Mientras en I856 la comunidad italiana ganaba numéricamente a los malteses, que se calculan en 7.II4 frente a 9.472 de italianos, es decir una diferencia de $2.35^{8}$ almas.

22 Las cifras que manejamos aquí están recogidas de diferentes obras, libros, y artículos sobre este tema. Véanse las tablas al final de este texto.

23 Donato, ob. cit., 2012. p. 7. 
Matrimonios por nacionalidad y por sexo en I 884

\begin{tabular}{|c|c|}
\hline Padre & Maltesa \\
\hline Francés & 28 \\
\hline Español & 03 \\
\hline Italiano & 16 \\
\hline Maltés & 84 \\
\hline Alemán & 01 \\
\hline Otros & 01 \\
\hline
\end{tabular}

Fuente: Ricoux René, La population européenne en Algérie pendant l'année 1884.

El aumento de la comunidad maltesa se culminó en el año I886, cuando se registraron 15.333 unidades, ocupando la tercera categoría de población extrajera europea por encima de alemanes, belgas y suizos juntos. A partir de I887 empezó a descender perdiendo anualmente unidades: en 189I se perdió el total de I.656 con respecto al año r 886 y en el año i 896 se estima que había 13.986, es decir una pérdida de I.509 comparándola con el año I89I y diez años más tarde (I9OI) se calcula que la comunidad maltesa no superaba las 13.250 personas ${ }^{24}$. El total de los europeos, incluidos los naturalizados, se calcula en 364.257 , donde la mayoría eran españoles $155.265^{25}$.

La pérdida del elemento maltés fue debida a causa de las represalias legislativas contra todos los emigrantes mediterráneos y, al mismo tiempo, a los efectos de las diferentes leyes de naturalización, donde se consideraban franceses nada más naturalizarse. Por otro lado, a partir de I88I se dirigían al vecino Túnez, un protectorado francés que no se les exigía mucho sacrificio para adaptarse, aprovechando la cercanía geográfica y las pocas horas de travesía para llegar.

\section{Malteses en Argelia: entre el rechazo y la aceptación}

Si Argelia para los españoles es la tierra de promisión, para los malteses, no obstante, es el Dorado, país donde no faltaba de nada: trabajo, riqueza y placer, un país de "oro" donde se asegura un futuro mucho

24 Demontés, ob. cit., 1906, pp. 52-53.

25 Ibid., p. 26. 
mejor que en el país de origen. Para un maltés, Argelia no es aquel lejano país latinoamericano, fabuloso o imaginario sino, al contrario, una tierra cercana geográficamente donde se puede llegar fácilmente con la certeza de tener mejor condición de vida nada más llegar. Pero estas ideas del maravilloso país no son fáciles de alcanzar ya que - como hemos mencionado anteriormente - la autoridad colonial en París y en Argel no mostraba mucho ánimo a la hora de recibirlos de manera "oficial", sino contrariamente, eran dejados a su suerte, sin control y sin restricción hasta I880, cuando empezaron a mostrar un rechazo a todo tipo de emigración mediterránea, enfocándose paralelamente en captar más a los franceses para la colonización ${ }^{26}$.

El crecimiento demográfico - ya resuelto después de ser un problema frente a la colonización - permite que las autoridades colonizadoras piensen en controlar las entradas de malteses y, sobre todo, de españoles, a los que siempre vieron con ojos de menosprecio. Es cierto que a partir de 1880 ya se oían voces que alertaban del peligro de las comunidades extranjeras, las cuales ponían en riesgo el equilibrio demográfico y, por consiguiente, todo el futuro de la Francia colonial en Argelia. Maurice Wahl, en I882 se manifestaba abiertamente contra la presencia de "estos muchos" extranjeros que podría poner en peligro el futuro de Francia: «la présence de tant d'étrangers constitue un embarras dans le présent et un péril pour l'avenir» ${ }^{27}$ y añade, refiriéndose más sobre la pertinencia y pertenencia de Argelia a Francia, en torno al control de las fronteras para organizar la llegada de extranjeros: «nous n'avons pas conquis l'Algérie pour en faire un pays cosmopolite; terre française elle est; terre française elle doit rester», y propone que «Il faudrait d'abord surveiller soigneusement l'arriver des émigrants, surtout des Espagnols, n'admettre que les gens pourvus de papiers en règle et de moralité constaté, expulser sans merci les vagabonds et les dangereux; toute l'hospitalité du monde ne saurait pas nous obliger à recevoir chez

26 A partir de 1848 la autoridad francesa ponía trabas que dificultaban la entrada de inmigrantes mediterráneos a Argelia, por ejemplo poseer 400 francos en efectivo para poder tener permiso de entrada.

27 Cf. Jeannine Verdes-Lerous, Les Français de l'Algérie de 1830 à aujourd'hui, une page d'histoire déchirée, París, Fayard, 2001, p. 205, citado en Marie Muyl, Les français de l'Algérie: socio-histoire d'une identité, Thèse de Doctorat, París I, 2007, p. 51. 
nous le rebut des autres peupless ${ }^{28}$. Efectivamente, en la Revue de l'Afrique Française se pone de manifiesto el peligro de la supremacía del elemento extranjero sobre el francés: «Mais quels colons devons-nous chercher le plus à attirer, les Français ou les étrangers? Et parmi ceux-ci, devons nous établir des distinctions?? ${ }^{29}$.

Cabe mencionar que este miedo y rechazo a las comunidades española y maltesa no es casualidad, sino que está fundado en hechos reales ${ }^{30}$ : en I84I, había en la región de Orán 2.999 del elemento español frente a r.606 de franceses. En toda la geografía argelina el total de los primeros asciende a 9.748 mientras los franceses se calculan en II.508 almas. En este mismo año se calcula que había 3.795 malteses en el este argelino, y en I845 más de 8.074, y en I851 el total es de 7.307. Hay que mencionar que en I843 había un total de 28.000 emigrantes franceses que venían a Argelia frente a 31.000 de nacionalidades europeas. Estas cifras se doblan en 1846 donde sólo en Argel se calcula que había 2.969 franceses frente a 6.356 de nacionalidad española ${ }^{31}$. Los españoles en 1858 representan el $28 \%$ de los europeos censados. Las dos décadas siguientes a esta fecha los españoles casi se igualan con los franceses: 26.365 frente a $27.772::^{32}$

Españoles y franceses en el Oranesado en I886

\begin{tabular}{|c|c|c|c|c|c|}
\hline & Mascara & Mostaganem & Orán & $\begin{array}{c}\text { Sidi Bel } \\
\text { Abbés }\end{array}$ & Tremecén \\
\hline Españoles & 6.701 & 5.951 & 58.670 & 14.855 & 4.648 \\
\hline Franceses & 7.775 & 11.093 & 30.485 & 6.615 & 5.994 \\
\hline
\end{tabular}

Fuente: Jordi, Jean-Jacques: Espagnol en Oranie: Histoire d'une migration. p. 28.

28 Ibid.

29 Rochaid Dahdah, "Les colons étrangers en Algérie-Tunisie", Rerue de l'Afrique Française, París, 1886, fasc. 19, tom. IV, p. 341.

$30 \mathrm{La}$ correspondencia entre el Consulado de Francia en Alicante y el Ministerio de Asuntos Exteriores en París recogida y clasificada por Manuel Valero Iváñez, nos da una visión bastante clara de las preocupaciones sobre la emigración clandestina, sobre todo del sur español y Argelia, así como las epidemias, el comercio y el trasporte marítimo. Véase: Valero Iváñez Manuel, "E1 Norte de África en la documentación del Consulado francés en Alicante durante el S. XIX", Anales de Historia Contemporánea, Universidad de Murcia, 1984, vol. 3, pp. 245-254.

31 Carette, loc. cit., 1856, p. 105.

32 Jean-Jacques Jordi, Espagnol en Oranie, Histoire d'une migration 1830-1914, Montpelier, Africa Nostra, 1986, p. 10. 
Ahora bien, desde que los franceses iniciaron la colonización de Argelia, los malteses habían mostrado su satisfacción de manera abierta. Por una parte, los malteses querían ver la tierra norteafricana bajo control de un país fuerte y occidental, y por otra parte, querían cambiar a los ingleses por franceses con el deseo de mejorar sus condiciones de vida $y$, sobre todo, oponerse a los británicos, quienes desde el comienzo del siglo XIX no habían hecho nada más que agravar los problemas ya existentes, tales los altos precios, el trabajo reservado a los ingleses, las diferentes enfermedades, epidemias, la sobrepoblación y las calamidades agrícolas. En efecto, las autoridades británicas a lo largo del siglo XIX no habían establecido mecanismos ni política que permitieran mejorar el nivel de vida de los malteses, sino contrariamente, habían seguido una política pasiva sin mostrar ningún compromiso ni responsabilidad para mejorar sus condiciones de vida.

No obstante, el porqué en este sentido es doble: por una parte, los ingleses no querían dispensar fondos públicos para organizar una emigración controlada y organizada (solución inmediata para salir de los problemas internos) ${ }^{33}$; y por la otra, querían que los malteses saliesen de Malta por sus propios medios, ya que éstos preferían el Mediterráneo a lugares más lejanos. Los más cercanos eran Argelia y luego el vecino Túnez, colonizados por Francia, potencia rival de los ingleses. Pero sí a partir de 1870 , sobre todo tras la crisis económica de 1873 , la autoridad maltesa se propuso organizar la emigración de acuerdo con las autoridades francesas en Argelia. Sin embargo, la respuesta de estos últimos era decepcionante, ya que no mostraban ningún interés en colaborar con ellos. Esta negativa se manifestó clara y rotundamente en I832, cuando se excluye al elemento maltés de cualquier plan de colonización ${ }^{34}$. Los malteses aunque capaces y sobrios para soportar la dureza de los trabajos en la primera fase de la colonización, eran menos deseados por las autoridades

33 Hay que recordarse que antes de esta fecha, existieron muchos intentos de organizar y oficializar la emigración maltesa a otros países, fracasados todos: La Cefalonia (1826-1832), La Guiana (1838-1841), Trípoli (1849-1850), Jamaica (1872-1874), Chipre (1878-1880), y Australia (1881-1884).

34 Para acercarse a este tema véase Xavier Yakono, "La régence d'Alger d'après l'enquête des commissions de 1833-1834”, Revue de l’Occident Musulmane et de la Méditerranée, 1966, vol. 1, núm. 1, pp. 229-244. 
francesas, ya que en su mayoría eran muy pobres, cualidad que les dejaba al margen de los emigrantes europeos deseados. También el maltés, por su carácter y su fisionomía se parecía al árabe, y eso lo convertía en el menos aceptado por los franceses y por las autoridades, como afirman los cónsules ingleses, son "des étrangers pour les quels les fonctionnaires français ont les moins de sympathie" 35 .

Esta negatividad sobre el elemento maltés también se mostraba a través de los escritos de la época. Efectivamente, los franceses desde los primeros años de la colonización mostraron miedo a la presencia de mahoneses y malteses, sobre todo en la ciudad de Argel. En I834, Genty du Bussy (1834: 84) escribe alertando de la presencia masiva de malteses: «nous avons à nous défendre des émigrations répétées des Baléares et de Malte; nous avons de sages précautions à prendre. En laissant à l'Europe entière la liberté de nous expédier des colons, restons au moins les maitres de ne les accepter que quand ils nous conviennent». Para los ingleses, los malteses eran considerados como orientales, son como dice Sir Victor Houlton (Chief Secretary): «ils nont absolument rien de l'Anglais dans leur caractère et ils acceptent une décision d'une autorité supérieur (...) dans un esprit entièrement oriental» ${ }^{36}$.

Los testimonios acerca de la comunidad maltesa son, en su mayoría, muy negativos, tanto de los responsables franceses e ingleses como de los simples colonos. El cónsul inglés describe, en I832, el trato de los franceses a los malteses de manera negativa, menos cordial y muy poco simpática: «les Français n'aiment pas du tout les Maltais et ne perdent jamais une occasion de les punir, si leur conduite n'est pas bonne; ils leur causent beaucoup d'ennuis» ${ }^{37}$. Igualmente la comunidad española no ha merecido muchos elogios por parte de los colonos franceses de la época ni tampoco por las autoridades coloniales en Argelia ${ }^{38}$. El colectivo maltés, en efecto, tuvo la misma suerte que ellos.

35 Donato, ob. cit., 2012, p. 8.

36 Houlton Victor, citado en Claude Liauzu, Histoire des migrations en Méditerranée Occidentale, Complexe, Coll. Questions au XXe. Siècle, 1996, p. 33.

37 Lettre du Consul Saint- John, 3 juin 1832, citado en Émile Temime, ob. cit., p.38.

38 Djamel Latroch, "Españoles en el Oranesado: emigrantes españoles en el oeste argelino (1830-920)”, Hesperia. Culturas del Mediterráneo, especial Argelia, 2014, vol.1, núm. 18, pp. 12-26. 
Pasados ya más de dos décadas, el rechazo a las comunidades mediterráneas es muy llamativo. Las dos comunidades emigran por razones económicas, buscando trabajo y tranquilidad para poder sobrevivir por causa de las miserables condiciones de vida en sus países de origen. Hay que recordar que, en su mayoría, son analfabetos, sin recursos económicos, trabajadores que ejercen funciones que ayudan al desarrollo político y económico de la empresa colonial: «Si certains hommes nétaient pas préférés à certains autres, les populations urbaines afflueraient tandis que la terre manquaient de bras; que déjà parmi les Espagnols et les Maltais, reçus avec tant de légèreté, la plupart exerçaient un trafic, un brocantage, et que bien peu avaient loué leur travail aux colons cultivateurs" 39 . Son como ya hemos mencionado anteriormente, muy poco deseados, no obstante, imprescindibles para la buena marcha de la colonización. El trabajo de los malteses como de otras comunidades mediterráneas son «des occupations, importantes, et même indispensables pour la bonne marche de l'entreprise coloniale, qui assure à longue une installation durable, avec la complicité des autorités, qui ne les favorisent guère, mais qui finissent tout de même par les accepter» ${ }^{40}$.

Por su parte, el autor de La colonisation de l'Algérie escribe en I856, mostrando este aspecto negativo sobre los malteses vistos por los colonos franceses: «les Maltais sont les étrangers pour lesquels la plupart des fonctionnaires et des colons français éprouvent le moins de sympathie. On leur trouve de la superstition et des allures grossières; on prétend qu'ils ne sont point à la hauteur de la civilisation» ${ }^{41}$. Casi todos los colonos franceses vieron a los malteses con ojos de menosprecio por su carácter físico y por la extrema pobreza que presentaban, aunque el cónsul francés en Malta había sido favorable a la emigración maltesa hacia Argelia, sobre todo en los primeros años de la colonización, por motivos políticos y religiosos. Efectivamente, los malteses no ponían resistencia ni miedo al estar en suelo argelino y de igual manera, eran muy católicos, lo que podía ayudar de modo efectivo a la cristianización de Argelia por ser cercanos al idioma árabe y a la climatología mediterránea ${ }^{42}$. Esta similitud entre las

39 Procès-verbaux et rapports de la Commission nommée par le Roi le 7 juillet 1833, París, Imp. Royale, 1834, p. 95.

40 Temime, ob. cit., 1987, p. 41.

41 Louis Baudicour, La colonisation de l'Algérie, ses éléments, París, Jacques Lecoffre, 1856, p. 181. 42 Nathalie Bernardie, Malte, parfum d'Europe, souffle d'Afrique, Burdeos, Coll. Iles et Archipels, 
lenguas árabe y maltés, así como la similitud de los aspectos físicos son, para Montezon, razones suficientes de mala fama de las dos etnias, a ojos franceses: "mais comme chaque médaille a son revers, ils (los malteses) tiennent de l'Arabe par la sobriété, ils sont aussi bérité de sa ruse, de sa fourberie et de son penchant au vol't3.

Tanto la autoridad colonial francesa como los intelectuales franceses prefieren que los franceses tomen el control de la vida política y económica de Argelia dejando en segundo lugar a las demás comunidades mediterráneas como auxiliares cuando se les necesiten. En este sentido P. Leroy se pone de acuerdo con la orientación de la autoridad colonial en París criticando a los "populistas"—según su propio decir- que mostraban resistencia y rechazo a esta política: «le principal colon de l'Algérie restera, d'ailleurs, toujours le Français, parce qu'il a plus de ressources d'esprit et de caractère, parce que c'est lui qui apporte les capitaux et qui s'entend le mieux à tirer parti de la terre et des hommes» ${ }^{44}$. Por su parte, Muarice Wahl describe los nuevos malteses recién llegados como los menos civilizados, ignorantes y violentos: "Les Maltais nouvellement déparqué ou qui vit dans l'intérieur n'est pas encore un civilisé. Il est rude de manières, ignorant, superstitieux, violent» ${ }^{45}$.

Ahora bien, el miedo continúo de perder el control sobre Argelia originado por la numerosa presencia de las diferentes colectividades de origen mediterráneo es, según parece, la principal causa del continuo rechazo a estas poblaciones, sobre todo a partir de I848 donde, efectivamente, la política migratoria francesa se caracterizó por apartar todas las comunidades menos deseadas de cualquier participación activa en Argelia, tolerando su presencia por necesidad más que por obligación. La emigración mediterránea, sobre todo la española y la maltesa, como señala el profesor Emile Temime, es una «Migration non désirée, migration de pauvres, migration utile par son travail et aussi par la fonction intermédiaire 1999, núm. 27, p. 107.

43 M.A. Montezon, La vérité sur l'Algérie suivie de détails et de considérations, París, Feydeau, 1851, pp. 33-34.

44 Leroy, ob. cit., 1887, p. 55.

45 Maurice Wahl, L'Algérie, París, Alcan Felix, 1903, p. 235. 
quelle peut remplir entre le colonisateur et le colonisé. Cette masse déshéritée est, par la présence, symbole de l'échec de la grande migration coloniale» ${ }^{46}$.

\section{El Dorado mediterráneo}

Cuando empezó el siglo XIX, Malta entró en una nueva fase de su historia. En el mes de diciembre de I80o, el gobierno británico declara oficialmente a la nación maltesa bajo su protección. Unos años antes, Francia se había interesado en ocupar Malta por razones de seguridad para sus posesiones y para el comercio. En I797, Francia envió al secretario de la legación francesa de Génova, Mathieu de Poussielgue, en una misión para extraer informaciones, y un año más tarde, Bonaparte declaró la soberanía de Francia sobre Malta, la cual no duró mucho. En junio de I802, el congreso nacional maltés declaró reconociendo al rey de Inglaterra como soberano de Malta, después de romper con el tratado de paz de Amiens firmado entre Francia y el Reino Unido el 25 de marzo de 1802 . Esta ruptura entre las dos potencias de mayor protagonismo internacional en el siglo XIX, lleva al gobierno de Londres a reivindicar, otra vez, la soberanía de Inglaterra sobre el territorio maltés en marzo de I8I4, cuando finalmente Malta y sus dependencias se declaran estar bajo la soberanía del rey de Inglaterra.

Desde I8I4 Malta es una colonia británica. Los ingleses no tenían como finalidad el desarrollo económico del país ni de los malteses, aunque Malta se sitúa geográficamente entre Egipto y Gibraltar, escala obligatoria y necesaria para los barcos para cargarse de carbón y de alimentos. Los malteses, sin embargo, no se aprovecharon de los recursos del tránsito en sus puertos ni del comercio con los países africanos. La decepción frente a los ingleses y a los problemas políticos y económicos del país agravaron mucho la vida diaria de los malteses que, desde i820, tuvieron que salir fuera del país para poder sobrevivir o, al menos, asegurar una vida mejor, que estar bajo dominio de los ingleses. El destino preferido fue a los países cercanos geográficamente como Argelia, Túnez, Trípoli, Egipto, Turquía e Italia donde, efectivamente, se instalaron.

46 Temime, ob. cit., 1987, p. 44. 
Desde I8I4 a 1829 habían salido de Malta un total de 5.000 personas con dirección a estos países. En el periodo entre 1825-184I, emigraron 28.500 y entre I842-I850 un total de 17.500 . En I825, el 6\% de la población maltesa había salido del país; en I84I aproximadamente el r8\% salen con dirección principalmente a Argelia que es "foyer d'appel" para ellos y en I885 alcanza el 36\%. En I829, la población maltesa se estima, según Miè$\mathrm{ge}^{47}$ a II 4.236 personas, donde 79.053 son analfabetos (69\%) y 25.083 (22\%) saben leer y escribir sin ningún otro conocimiento más. Y en I842, según C. Liauzu ${ }^{48}$, II7.000 unidades. Hay que esperar a I830, fecha de la ocupación de Argelia, para que se produzca el inicio de los flujos migratorios hacia el país vecino; un país que responde a sus necesidades económicas y sociales. Cabe mencionar por último que 1836 el total de la población maltesa se sitúa alrededor de I23.I48 personas y un año después desciende a 120.792. Este descenso es debido a la emigración maltesa a Argelia principalmente ( 4.047 personas) y, claro está, a la mortalidad causada por el cólera de 1836, donde se estima que Malta había perdido 4.I55 almas.

La emigración de los malteses a Argelia viene condicionada por múltiples motivos tanto políticos como socioeconómicos. Desde 1813, reinaba en Malta el cólera, que se repitió en I830 (750 muertes) y en I837 (4.I55 muertes). Por otro lado, en I824, el algodón de Egipto se vende mucho más barato que el maltés en la propia tierra maltesa tras años seguidos de malas cosechas, provocando un gran pesimismo entre la población. Además la agricultura es muy escasa debido a la naturaleza del suelo y la escasez del espacio cultivable que se calcula en $256 \mathrm{~km}^{2}$ en 1829 . En este mismo año, se calcula que había Io.617 pobres de 23.132 que no tenían trabajo; mientras 2.333 son funcionarios del gobierno ${ }^{49}$. Por otro lado y demográficamente hablando, la densidad maltesa a mediados del s. XIX es la más alta en todo el Mediterráneo: en I829, 446 hab. $/ \mathrm{km}^{2}$ mientras 380 hab. $/ \mathrm{km}^{2}$ en 1837 ; y en 1842,372 hab. $/ \mathrm{km}^{2}$. No obstante, la tasa de natalidad oscila entre $35 \%$ a $40 \%$ (desde 1820 a 1829 son 33.126 nacidos frente a 22.967 de mortalidad: 10.I39 unidades de diferencia). En I867-68 se produjo una crisis de alimentos que a su vez provocó la subida de precios.

47 M. Miège, Histoire de Malte, Bruselas, Grégoire et Wouters, 1841, tomo 1, pp. 106-107.

48 Liauzu, ob. cit., 1996, p. 32.

49 Miège, ob. cit., 1841, p. 39-42. 
Aparte de estos problemas, hay otros que obligan a los malteses a emigrar de manera casi obligatoria a Argelia. Miège en su obra Histoire de Malte, los resume como sigue:

L'inamovibilité n'était pas assurée aux juges; les emplois supérieurs étaient toujours l'apanage des anglais; les changements opérés dans les tarifs, loin d'avoir soulagé le peuple, n'avaient eu pour résultat que aggraver sa misère; l'agriculture ne recevait pas l'encouragement; le commerce se restreignait [...] l'instruction publique était négligée pour les classes supérieures ${ }^{50}$.

Hay que recordarse que los malteses son muy católicos y están muy ligados a la religión católica (99\%). La familia para ellos es algo mucho más sagrado, casarse temprano para no caer en adulterio, así como tener una familia numerosa es una prueba de ser fiel a la religión. Efectivamente, para una familia maltesa de mediados del s. XIX es normal tener siete $\mathrm{u}$ ocho hijos de media por hogar. Las parejas se casan muy jóvenes. La natalidad tan alta, además de la sobrepoblación en una superficie saturada - la más densa en todo el Mediterráneo- provocaba todo tipo de problemas sociales graves. A partir de I830 se propuso organizar esta situación reduciendo la natalidad al aumentar la edad para casarse, y la negación a parejas de extrema pobreza a contraer matrimonio, medida que fracasó sin resultados notables. Frente a este fracaso, el gobierno optó por la emigración como una medida para solucionar los problemas de sobrepoblación y de la pobreza. En I838, por ejemplo el periódico Il mediterraneo pone énfasis en la preocupación de los malteses por la falta de subsistencia y alimentos ${ }^{51}$.

Aparte de lo anterior expuesto, la lengua maltesa, cercana al idioma árabe, la geografía semejante a la maltesa y su proximidad, el mar, el clima, son entre otros, factores que han ayudado de manera directa a la instalación de la colectividad maltesa en el litoral oriental argelino. Son comerciantes, cultivadores y agricultores en su mayoría, de clases desfavorables que ni siquiera aseguran su comida diaria, prefieren el norte de África, especialmente Argelia, más que las posesiones británicas en

50 Ibid., p. 518.

51 Il Mediterraneo, 19 de septiembre de 1838, citado en Jean-Marie Moissec, "Transition démographique et migration a Malte”, Cabiers de la Méditerranée, 1989, núm. 39, p.128. También citado en: Nathalie Bernardie, ob.cit., p. 95. 
otras tierras, con la certeza de progresar, con predisposición a adaptarse a cualquier situación tanto con los colonos de diferentes nacionalidades como con los argelinos y los judíos. Nada más llegar al litoral argelino, se ponen manos a la obra: unos — más afortunados - llevan con ellos sus cabras, único capital para su venta o explotación en Argelia. Otros, se relacionan con los judíos comerciando; otros, conocedores de la lengua árabe, trabajan como interpretes entre argelinos y franceses; otros conocedores de la marina, trabajan como buceros, cargadores y pescadores en los puertos de Bona y Skikda.

Ya pasados unos cuantos años, se adaptan al clima y a la nueva vida en tierras norteafricanas donde, efectivamente, trabajan por su cuenta propia tras duros años de ahorro, vendían carne de cabra de "raza maltesa" en las ciudades a los colonos y a los habitantes de la ciudades; unos vendían frutas y legumbres que ellos mismos cultivan en pueblos colindantes ${ }^{52}$, otros prefieren trabajar como comerciantes ambulantes vendiendo artículos fabricados por ellos mismos. Los malteses o los "árabes cristianos", calificativo que les dan por ser cercanos al idioma árabe y por parecerse a la fisionomía norteafricana, saben sacar partido de las oportunidades que se les brindaban. Sobrios, muy trabajadores, ahorradores, y amantes a la calma y la tranquilidad, a diferencia de los españoles, su única finalidad es ganar dinero lo más pronto posible para salirse tempranamente de sus miserias. La política, en efecto, les importaba poco. En el periódico Progrès de l'Algérie en I89I, se escribe que "les Maltais, il faut l'avouer, n’ont pas, n'ont jamais eu l'ardeur guerrière qu'ont presque toutes les populations européennes, ils aiment mieux cultiver des carottes et des navets dans un champ, vendre des denrées ou des liquides dans une boutique ou un cafe"

En las primeras décadas forman una sociedad aparte, no se mezclan con los franceses, sino que viven en su mundo. Sin embargo, con el tiempo empiezan a tener relaciones comerciales y luego sociales con casi todos los componentes de la sociedad argelina. Reservan su lengua y sus costumbres como señas de identidad e incluso su manera de vestirse. Pero a finales del siglo Xıx, ya empiezan a tener cierto comportamiento francés, hablando la lengua de Molière, se relacionan con todos, por motivos

52 Montezon, ob. cit., 1851, p. 10.

53 Progrès de l'Algérie. Constantina, mardi 15 septembre 1891, núm. 174. 
de sus comercios, adoptando hábitos y ritos franceses. Los hijos de las familias modestas iban a los colegios franceses e incluso a París para terminar sus estudios: «au bout de deux ou trois générations, on ne reconnait plus le paysan fruste et superstitieux qui à débarqué jadis pieds nus et la veste sur le bras» ${ }^{54}$. Se visten a la moda y sólo tienen relación con su país natal al necesitar documentos administrativos o informarse sobre algún trámite administrativo. Las mujeres, ya mayores de edad, son solicitadas en matrimonio por sus compatriotas: "à peine en âge de se marier, elles sont demander par leurs compatriotes. Le mariage n'est pas attendu longtemps (...) gardée a vue, ne peut plus sortir de la maison... ${ }^{55}$.

La labor de los malteses en Argelia fue sorprendentemente considerable. En la agricultura habían introducido técnicas para aumentar la productividad desde los primeros años de su instalación, la carne y el queso de las cabras de raza maltesa tuvieron fama entre colonos y argelinos por su calidad y su baratez. Otros con más suerte, ocupan altos grados en el ejército francés, como el caso del barón de Piro que fue coronel en Constantina en I853; el capitán M. Perini que sirvió durante treinta años hasta su muerte en Constantina, el teniente André Gatt (Abderrahmane el Malti) muerto en 1897, nombrado Caballero de la Legión de Honor por su trabajo. Aparte de los militares, algunos malteses han tenido fortunas muy considerables en Argel y Constantina ${ }^{56}$, tras trabajar duramente como agricultores o comerciantes, otros, ya adinerados, profesaban el "comercio del dinero", competidores con los judíos o algunos árabes ${ }^{57}$. Otros, con nivel de altos estudios, profesaban la medicina, como el caso de Charles Eugène Finech, nacido en Malta y muerto en Bona en I842.

\section{Conclusiones y APÉNDice estadístico}

La comunidad maltesa al igual que otras comunidades mediterráneas fue la menos deseada por la Francia colonial en las dos primeras décadas de la colonización debido a su propia naturaleza. El miedo a perder el

54 R. Vadala, "Lémigration maltaise en pays musulmans", Revue du Monde Musulman, 1911, vol. XIV, núm. 1, p. 48.

55 Baudicour, ob. cit., 1856, p. 181.

56 Cf. Wahl, ob. cit., 1903, p. 235.

57 Demontés, ob. cit., 1906, p. 455. 
control de Argelia y la pasividad de la llegada de colonos franceses permitió que las comunidades mediterráneas se instalesen espontáneamente en Argelia, toleradas para solucionar el desequilibrio demográfico, y luego fueron vistas como una amenaza frente a la seguridad de la empresa colonial.

Población maltesa en Argelia

\begin{tabular}{|c|c|c|c|}
\hline Año & Malteses & Año & Malteses \\
\hline 1833 & 1.213 & 1861 & 9.378 \\
\hline 1836 & 1.802 & 1866 & 10.627 \\
\hline 1841 & 3.795 & 1872 & 11.512 \\
\hline 1845 & 8.047 & 1876 & 14.220 \\
\hline 1851 & 7.307 & 1877 & 14.313 \\
\hline 1856 & 7.114 & 1881 & 15.402 \\
\hline
\end{tabular}

Fuente: René Ricoux, La démographie figurée de l'Algérie (1880).

Natalidad maltesa en Argelia I876-I90o

\begin{tabular}{|c|c|c|c|c|c|}
\hline Año & nacimientos & Año & nacimientos & Año & Nacimientos \\
\hline 1876 & 518 & 1885 & 574 & 1894 & 471 \\
\hline 1877 & 532 & 1886 & 584 & 1895 & 398 \\
\hline 1878 & 522 & 1887 & 539 & 1896 & 419 \\
\hline 1879 & 527 & 1888 & 490 & 1897 & 430 \\
\hline 1880 & 500 & 1889 & 514 & 1898 & 394 \\
\hline 1881 & 569 & 1890 & 404 & 1899 & 438 \\
\hline 1882 & 582 & 1891 & 411 & 1900 & 452 \\
\hline 1883 & 608 & 1892 & 379 & & \\
\hline 1884 & 600 & 1893 & 422 & & \\
\hline
\end{tabular}

Fuente V : Demontés: Le peuple algérien, essai de démographie algérienne. (1906). 
72 Djamel Latroch

Mortalidad maltesa en Argelia 1876-1902

\begin{tabular}{|c|c|c|c|c|c|}
\hline Año & mortalidad & Año & mortalidad & Año & Mortalidad \\
\hline 1876 & 373 & 1885 & 455 & 1894 & 332 \\
\hline 1877 & 407 & 1886 & 479 & 1895 & 412 \\
\hline 1878 & 569 & 1887 & 497 & 1896 & 356 \\
\hline 1879 & 399 & 1888 & 447 & 1897 & 267 \\
\hline 1880 & 412 & 1889 & 704 & 1898 & 296 \\
\hline 1881 & 438 & 1890 & 394 & 1899 & 305 \\
\hline 1882 & 458 & 1891 & 480 & 1900 & 307 \\
\hline 1883 & 406 & 1892 & 347 & 1901 & 341 \\
\hline 1884 & 468 & 1893 & 378 & 1902 & 272 \\
\hline
\end{tabular}

Fuente: V. Demontés, Le peuple algérien, Essai de démographie algérienne (1906).

Población maltesa y total de europeos en Argelia

\begin{tabular}{|c|c|c|}
\hline Año & Malteses & Total de europeos \\
\hline 1833 & 1.213 & 7.812 \\
\hline 1836 & 1.802 & 14.561 \\
\hline 1841 & 3.795 & 37.374 \\
\hline 1845 & 8.047 & 95.321 \\
\hline 1851 & 7.307 & 131.283 \\
\hline 1856 & 7.114 & 160.798 \\
\hline 1861 & 9.378 & 192.646 \\
\hline 1866 & 10.621 & 217.099 \\
\hline 1872 & 11.512 & 245.117 \\
\hline 1876 & 14.220 & 311.462 \\
\hline 1881 & 15.402 & 385.362 \\
\hline 1886 & 15.533 & 436.457 \\
\hline 1891 & 14.677 & 485.973 \\
\hline 1896 & 13.986 & 536.006 \\
\hline 1901 & --- & 583.844 \\
\hline
\end{tabular}

Fuente: V. Demontès : Le peuple algérien, essais de démographie algérienne (1906) 